\title{
Testing the self-cleaning properties of a coordination polymer surface
}

\author{
Artur P. Terzyk ${ }^{1}$ (D) Grzegorz S. Szymański ${ }^{1}$ - Emil D. Korczeniewski ${ }^{1} \cdot$ Paweł Bryk $^{2}$ · Adam Bieniek ${ }^{1}$. \\ Paulina Bolibok $^{1} \cdot$ Michał Chodkowski $^{2} \cdot$ Piotr Kowalczyk $^{3} \cdot$ Marek Wiśniewski $^{1} \cdot$ Pilar Ferrer $^{4} \cdot$ Ivan da Silva $^{5}$
}

Received: 4 October 2018 / Accepted: 19 November 2018 / Published online: 29 November 2018

(c) The Author(s) 2018

\begin{abstract}
It is well established that self-cleaning can be related to the hydrophobic or hydrophilic nature of a surface. Using adsorption chromatography, molecular simulations and wetting dynamics measurements, the self-cleaning properties of a new, strongly water resistant and hydrophilic cystine-containing coordination polymer (CP) were tested. Adsorption isotherms of $n$-octane and methanol were determined in the range of 313-343 K. Next the isosteric enthalpy of adsorption and the change in adsorption entropy were calculated to explain higher adsorption of methanol than $n$-butane. Performed chromatographic tests, molecular dynamics simulations and wetting dynamics experiments additionally prove that the $\mathrm{Zn}(\mathrm{Cys})_{2} \mathrm{CP}$ is a promising material for the application in the preperation of self-cleaning surfaces or coatings.
\end{abstract}

\section{Introduction}

It is well established that the self-cleaning technologies are among the most important achievements of biomimetics. As it was pointed out by Ganesh et al. self-cleaning has many important applications (cleaning of glass, textiles, solar batteries etc.) (Ganesh et al. 2011). Self-cleaning can be the native property of a surface and/or can be introduced using different coatings. There are two major categories of selfcleaning surfaces: hydrophobic (Varshney and Mohapatra

Electronic supplementary material The online version of this article (https://doi.org/10.1007/s10450-018-9987-5) contains supplementary material, which is available to authorized users.

Artur P. Terzyk

aterzyk@chem.umk.pl

1 Faculty of Chemistry, Physicochemistry of Carbon Materials Research Group, Nicolaus Copernicus University in Toruń, Gagarin Street 7, 87-100 Toruń, Poland

2 Department for the Modeling of Physico-Chemical Processes, Maria Curie-Skłodowska University, 20-031 Lublin, Poland

3 School of Engineering and Information Technology, Murdoch University, Murdoch, WA 6150, Australia

4 Diamond Light Source, Harwell Science and Innovation Campus, Chilton, Didcot OX11 ODE, UK

5 Rutherford Appleton Laboratory, ISIS Neutron and Muon Source, Science and Technology Facilities Council, R3 UG.15, Harwell Campus, Didcot OX11 0QX, UK
2018; Yu et al. 2018; He et al. 2018) and hydrophilic (Prince et al. 2014). In the case of hydrophobic self-cleaning surfaces the repelling of water from a substrate causes the rolling of a droplet across a surface and the dirt is carried away with the droplet. This effect is observed for example for the Lotus leaves (Crick and Parkin 2010; Yu et al. 2014). In the case of hydrophilic surfaces the self-cleaning is due to the spreading of water on a surface.

Recently some new self-cleaning systems have been proposed utilizing the photocatalytic effect for the degradation of organic pollutants adsorbed on a surface (Yusof et al. 2018). Moreover some "smart" surfaces have been also developed and the self-cleaning effect can be UV (Kaner et al. 2017; Pifferi et al. 2015) or laser-induced (Zheng et al. 2016).

In this study we present the experimental data and give an insight into the molecular mechanism of the self-cleaning process. A hydrophilic, cysteine (Cys) containing coordination polymer $(\mathrm{CP}) \mathrm{Zn}\left(\mathrm{C}_{3} \mathrm{H}_{5} \mathrm{NO}_{2} \mathrm{~S}\right)_{2}$ is applied for this purpose (Ferrer et al. 2014). This $\mathrm{CP}$ is strongly water-resistant and, as it is shown in our study, the adsorbed hydrocarbon molecules are easily removed from its surface by polar molecules i.e. methanol and/or water. The experimental results are supported by molecular simulations. To the best of our knowledge, this is the first study reporting the self-cleaning properties of $\mathrm{CP}$ surfaces. 


\section{Experiment}

\subsection{Coordination polymer}

A $\mathrm{Zn}(\mathrm{Cys})_{2} \mathrm{CP}$ was obtained using the procedure reported by Ferrer et al. (2014). The structure was confirmed by the XRD, FTIR thermal and elemental analysis. This CP is nonporous (the BET surface area is equal to $96 \mathrm{~m}^{2} / \mathrm{g}$ ). The crystallographic data and the structure of this $\mathrm{CP}$ were reported previously (Ferrer et al. 2014).

\subsection{Chromatographic measurements}

The chromatographic investigations were carried out using a Chrom 4 gas chromatograph with a flame ionization detector (FID). A computer was connected to the gas chromatograph to control, acquire and process the chromatographic data. The adsorbent was placed in glass column $(30 \mathrm{~cm} \times 2 \mathrm{~mm}$ I.D. $)$ with an absorbent bed length of $22 \mathrm{~cm}$, which corresponded to $0.37 \mathrm{~g}$ of $\mathrm{Zn}(\mathrm{Cys})_{2}$ used. Before adsorption experiments, the column with the adsorbent was conditioned at $403 \mathrm{~K}$ for $8 \mathrm{~h}$ under a flow of helium.

Methanol and $n$-octane (A.R. grade) were used as adsorbates. The adsorbates were injected into the column by means of a Hamilton microsyringe. The size of the injected samples was $0.5 \mu \mathrm{l}$. The temperature of the injection device was set at $373 \mathrm{~K}$ and $433 \mathrm{~K}$ for methanol and $n$-octane, respectively. Additionally in some experiments, to investigated the effect of water on $n$-octane adsorption, dosed different amounts of water $(1,2,4 \mu \mathrm{l})$ before as well after $n$-octane injection.

Adsorption isotherms were determined in the range of $313-343 \mathrm{~K}$ in $10 \mathrm{~K}$ steps at carrier gas flow-rates 30 and $60 \mathrm{~cm}^{3} / \mathrm{min}$ (measured by means of a bubble gauge). The measured flow-rates at room temperature and atmospheric pressure were corrected for temperature and pressure drop (Paryjczak 1987). Adsorption isotherms were determined using the peak profile method (Paryjczak 1987; Słomkiewicz 2006). The obtained peaks were unsymmetrical for all adsorption systems. This points to the effect of diffusion on the rate of establishment of adsorption equilibrium. Therefore, in calculation of the adsorption isotherms account was taken of the diffusion effect in accordance with the postulates of Dollimore et al. (1970). The isosteric enthalpy of adsorption $\left(q^{s t}\right)$ was calculated using isosteres obtained from adsorption data (i.e. using plots of partial pressures $(\ln p)$ versus temperatures $(1 / T)$ at constant coverages $\theta$ ) according to the Clausius-Clapeyron equation (Paryjczak 1987; Grob 1995):

$q^{s t}=R\left[\frac{\partial \ln p}{\partial(1 / T)}\right]_{\theta=c o n s t}$

where $R$ is the gas constant.
The change in the entropy of adsorption $(\Delta S)$ was calculated with respect to the liquid state using:

$\Delta G=R T \ln \left(\frac{p}{p s}\right)=\Delta H-T \Delta S$

where $\Delta G$ and $\Delta H$ are the change in free enthalpy, and the so-called "pure" enthalpy of adsorption, respectively, $p$ and $p_{s}$ are the equilibrium and saturated vapour pressures. The values of the saturated vapour pressures (Yaws 2003) and the enthalpy of condensation (Majer and Svoboda 1985) applied during calculations are provided in the Electronic Supplementary Material.

\subsection{Molecular simulation of wetting and self-cleaning}

All molecular dynamics (MD) simulations were performed using the OpenMM molecular simulation toolkit (Eastman et al. 2013). As in our previous studies (Włoch et al. 2017a, b, 2018) the TIP4P/2005 (Abascal and Vega 2005) water model was applied. The OPLSAA force field parameters were taken from the TINKER package (Robertson et al. 2015; Lagardère et al. 2018), while the parameters for Zn were taken from the study of Li et al. (2013). First the wetting of the bare CP surface was determined. Next, to study the self-cleaning effect, the monolayer adsorption of hydrocarbons was simulated $\left(\mathrm{C}_{10} \mathrm{H}_{22}, \mathrm{C}_{24} \mathrm{H}_{50}\right.$ and $\left.\mathrm{C}_{55} \mathrm{H}_{112}\right)$. Lastly, the water drop was placed on top of the equilibrated alkane monolayer, and the wetting properties were determined again. The hydrocarbon molecules could freely move on a surface (see Electronic Supplementary Material for further simulation details and results).

\subsection{Dynamics of wetting}

To check the dynamics of wetting six $\mathrm{Zn}(\mathrm{Cys})_{2}$ samples were prepared following the procedure described in Electronic Supplementary Material. Three of them were thermally desorbed $(\mathrm{T}=393 \mathrm{~K})$ and the remaining three were equilibrated with the saturated $\mathrm{C}_{10} \mathrm{H}_{22}$ vapour at the $\mathrm{T}=300 \mathrm{~K}$. Next the wetting process was performed using the system described in the Electronic Supplementary Material, and the movies were recorded.

\section{Results and discussion}

\subsection{Chromatographic data}

From the data collected in Figures S1 and S2 (Electronic Supplementary Material) one can observe that the carrier gas flow-rate $\left(V_{H e}=30\right.$ and $\left.60 \mathrm{~cm}^{3} / \mathrm{min}\right)$ has small influence 
on the $n$-octane adsorption isotherms determined in the range of $\mathrm{T}=313-343 \mathrm{~K}$. In contrast, we observe the influence of this gas flow-rate on methanol adsorption. This is why for our calculations we used the data determined at the flow $30 \mathrm{~cm}^{3} / \mathrm{min}$. As it can be seen from the data collected in Figures $\mathbf{S} 2 \mathrm{c}$ and $\mathrm{S} 2 \mathrm{~d}$ the reproducibility of measurements is very good.

Figure 1 shows the comparison of methanol and $n$-octane adsorption isotherms on $\mathrm{Zn}(\mathrm{Cys})_{2}$ determined for the studied temperatures. In the case of both adsorbates one can observe the linear parts of adsorption isotherms at low coverages, and the decrease of adsorption with the rise in temperature (due to the exothermic nature of the process).

Moreover, for all studied temperatures the adsorption of $n$-octane is smaller than the adsorption of the methyl alcohol (the same sequence of adsorption isotherms is observed at the flow-rate of $60 \mathrm{~cm}^{3} / \mathrm{min}$ - see Figure S3 in the Electronic Supplementary Material).

Figure 2 shows the comparison of the isosteric enthalpy of adsorption (calculated using Eq. 1) and the change in the entropy of the process (Eq. 2). One can conclude that the $q^{s t}$ values are more negative for $n$-octane than for methanol. Moreover, the absolute value of methanol adsorption enthalpy progressively decreases due to heterogeneity of the studied CP surface. The rise in the absolute enthalpy value (starting at adsorption ca. $20 \mu \mathrm{mole} / \mathrm{g}$ ) is caused by adsorption of subsequent methanol molecule forming surface associates, because it is well known that the adsorption mechanism of polar molecules is usually dominated by clustering around the adsorption sites (Furmaniak et al. 2008). It has been well established that the metal nodes serve as the CP adsorption centers for hydrogen and polar molecules (Rosi et al. 2003). Thus one can expect, that in the case of methanol we observe donor-acceptor interactions with exposed zinc surface cations. As it can be observed in Fig. $2 \mathrm{~b}$ the absolute value of the $n$-octane adsorption enthalpy slightly increases at small coverages and next remains almost constant. The enthalpy steadiness is caused by the decrease of the solid-fluid interactions with the concomitant increase of the fluid-fluid interactions, upon rising the surface coverage (Vernov and Steele 1991). It is well proved that the non-polar molecules (like alkanes) during adsorption may form different ordered structures due to adsorbate-adsorbate interactions (Gilbert et al. 1998). Since the $n$-octane molecule does not possess the dipole moment, the adsorption in this case is not very sensitive to the presence of the surface polar sites. Thus, the observed in Fig. 1 (and Figure S3) better methanol than $n$-octane adsorption causes more positive entropy change, in comparison to the liquid state (Fig. 2c, d). We conclude that the $n$-octane molecules due to the strong affinity for the CP surface, as well as due to the fluid-fluid interactions are less mobile than the adsorbed methanol molecules.

The fact that the adsorption of methanol is stronger than the adsorption of $n$-octane has been also corroborated by the results collected in Fig. 3. In this figure we show
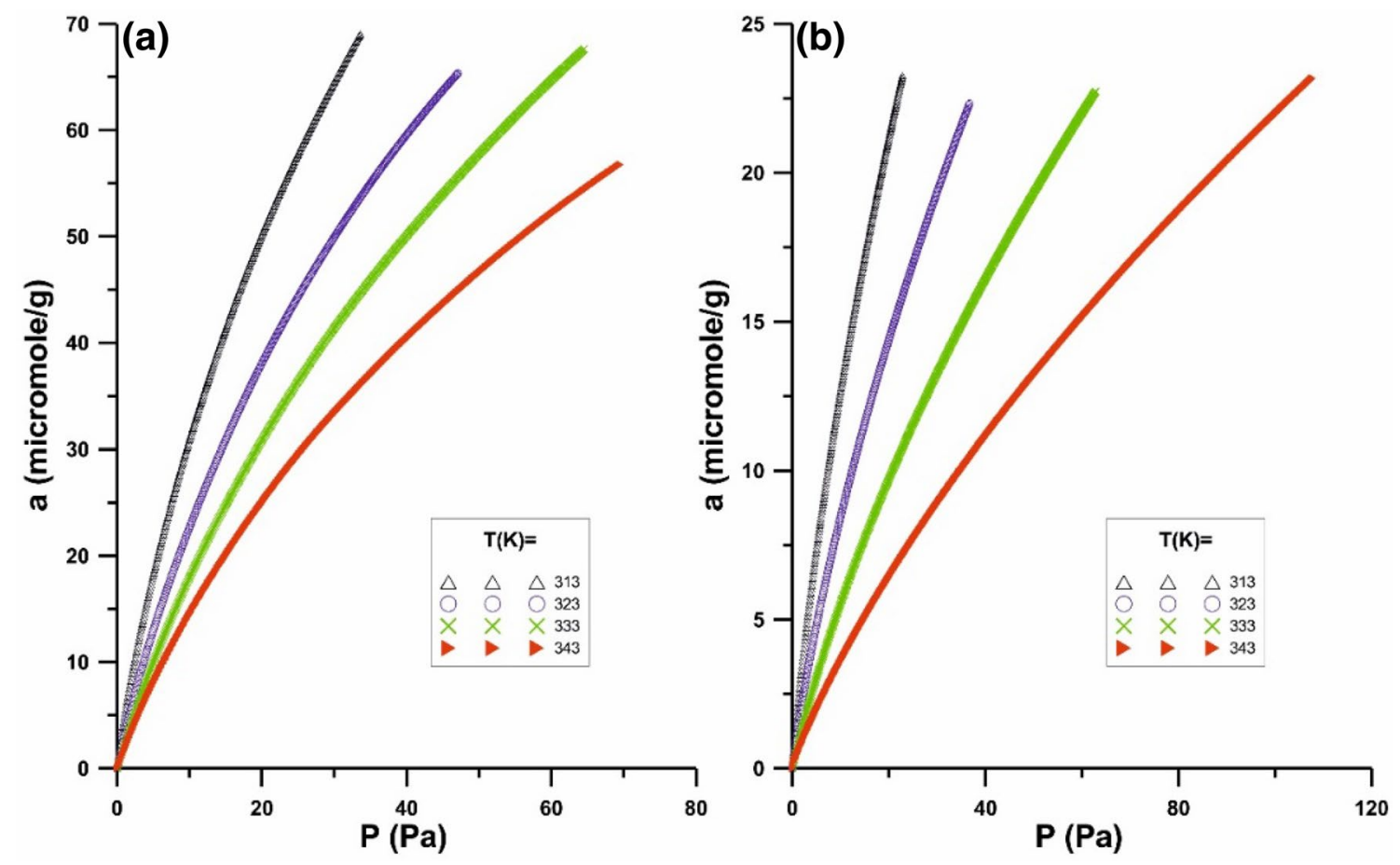

Fig. 1 The temperature dependence of methanol (a) and $n$-octane (b) adsorption isotherms on $\mathrm{Zn}(\mathrm{Cys})_{2}$ at $V_{H e}=30 \mathrm{ml} / \mathrm{min}$ 


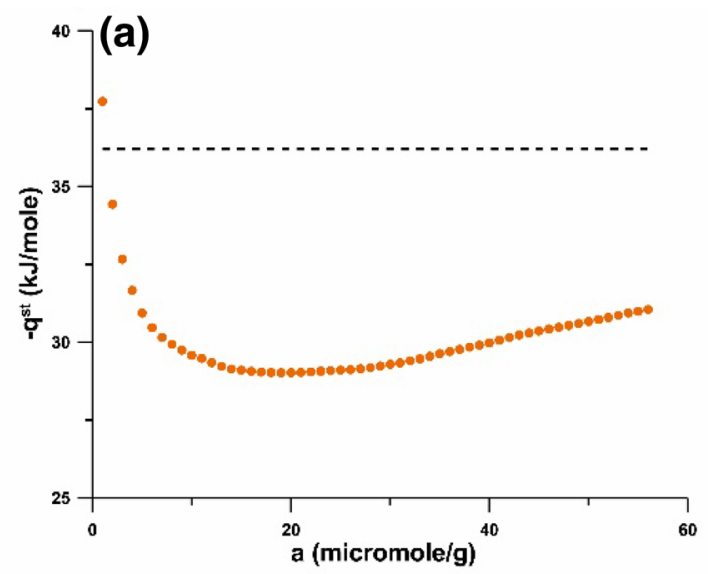

(c)

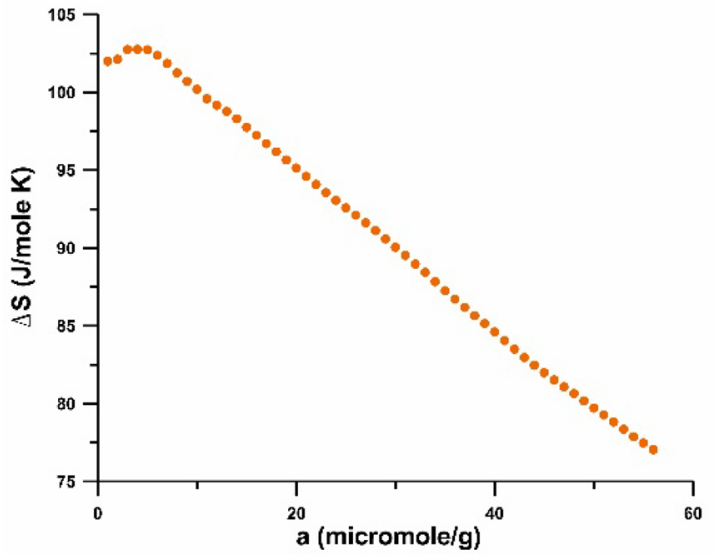

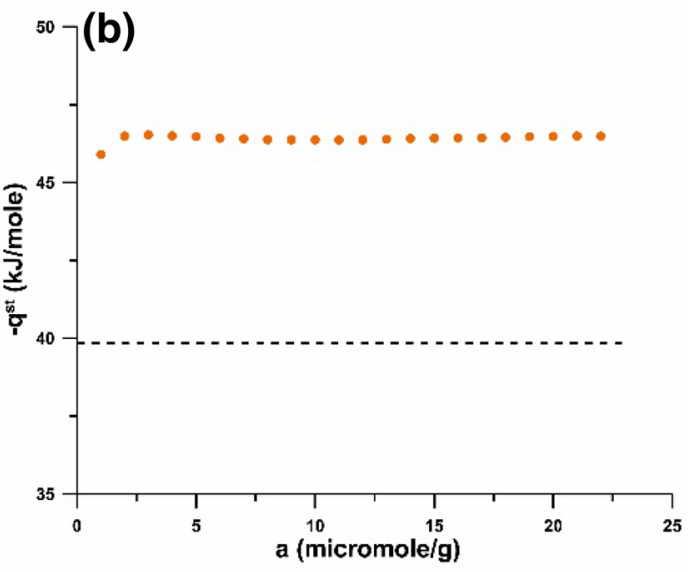

(d)

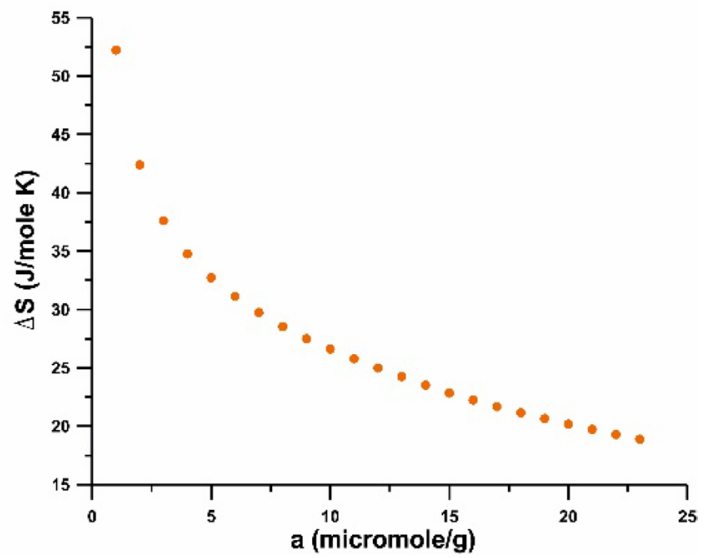

Fig. 2 The comparison of isosteric enthalpy (a, b) and the change in differential molar entropy of adsorption (c, d) of methanol (a, c) and $n$-octane $(\mathbf{b}, \mathbf{d})$ on $\mathrm{Zn}(\mathrm{Cys})_{2}$. Horizontal dashed lines show the value of the enthalpy of condensation

the chromatograms of dosed $n$-octane followed by injection of different volumes of methanol (Fig. 3a) and water (Fig. 3b) into the column. We note that the addition of polar molecules decreases the $n$-octane retention time. Thus it can be concluded that $n$-octane is expelled from the adsorbed phase by polar methanol and/or water molecules.
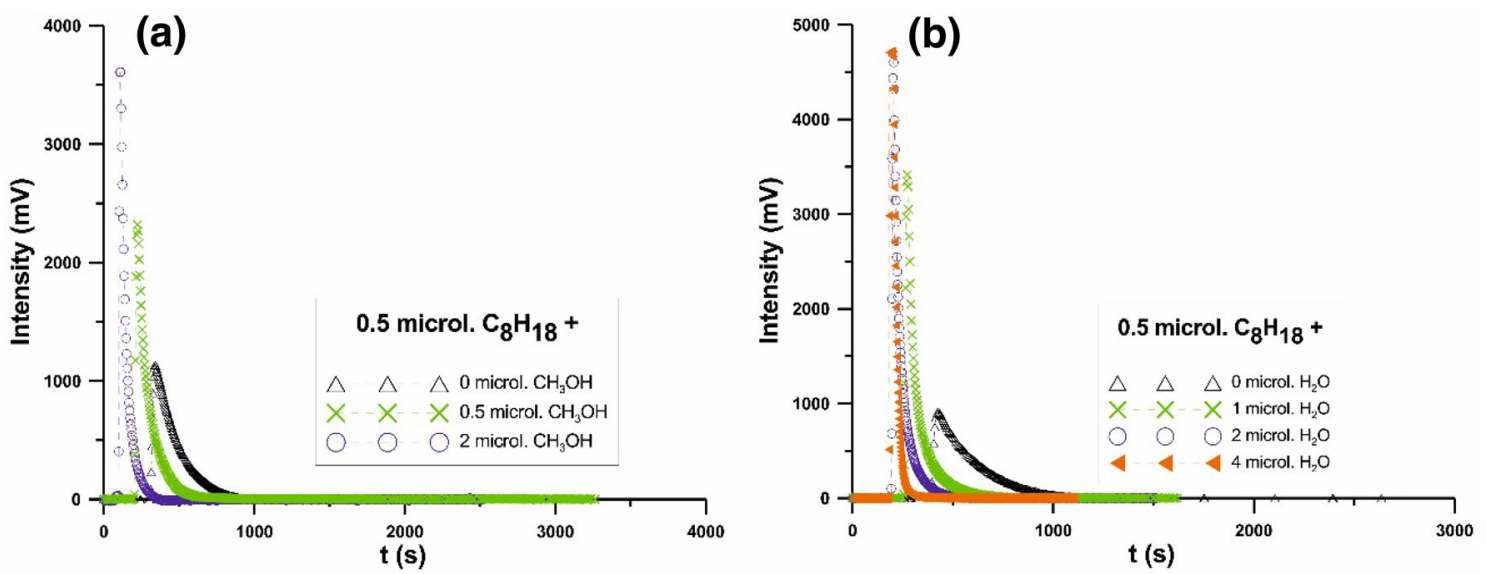

Fig. 3 Chromatograms of dosed $0.5 \mu$ octane followed by injection of different volumes of methanol (a) and water (b) into the column at $V_{\mathrm{He}}=30 \mathrm{ml} / \mathrm{min}$ 


\subsection{Molecular simulation and wetting dynamics results}

Figure 4 collects the results of MD simulation for water nanodroplet sitting on the considered CP surface. One can observe that the complete wetting occurs, and the resulting water contact angle is equal to zero. It means, that the studied CP surface is strongly hydrophilic, and completely wetted by water at the room temperature. However, more interesting are the results showing the behavior of water nanodroplet on the studied CP surface covered by an $n$-alkane monolayer. Collected in Fig. 5 results for $n$-decane show that the equilibrated hydrocarbon monolayer (see Fig. 5 for $\mathrm{t}=0.5 \mathrm{~ns}$ ) is completely expelled by water molecules forming the nanodroplet (see Fig. 5 for $\mathrm{t}=2.5,5$ and $10.5 \mathrm{~ns}$ ). The same situation is observed for other $n$-alkane molecules (see Figure S4 in the Electronic Supplementary Material), leading to conclusion about the self-cleaning properties of the studied CP surface. It is interesting to note, that even
$\mathrm{C}_{55} \mathrm{H}_{112}$ molecules (being solid at the normal conditions) are successfully expelled by the nanodroplet of water sitting on the studied CP surface (Figure S4). This indicates that the self-cleaning behaviour is robust.

Figure 6 collects the results of wetting dynamics measurements. As one can observe, macroscopic water droplet wets the dry $\mathrm{Zn}(\mathrm{Cys})_{2}$ surface very fast (around $1 \mathrm{~s}$ ) however, the wetting of $\mathrm{Zn}(\mathrm{Cys})_{2}$ equilibrated with $\mathrm{C}_{10} \mathrm{H}_{22}$ vapour is around 5 times longer. This is the confirmation of the chromatography and simulation results presented above.

\section{Conclusions}

$\mathrm{Zn}(\mathrm{Cys})_{2} \mathrm{CP}$ adsorbs better polar molecules than $n$-alkanes. The mechanism of low-coverage adsorption in the case of $\mathrm{CH}_{3} \mathrm{OH}$ is controlled by adsorption on polar surface sites and clusterisation. For $n$-octane adsorption process is dominated by adsorbate-adsorbate interactions. Higher affinity

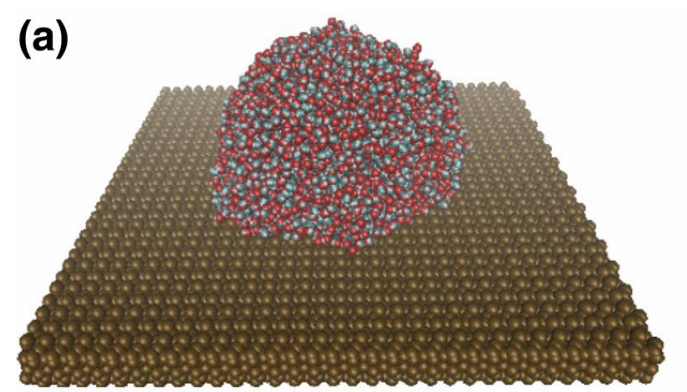

(b)
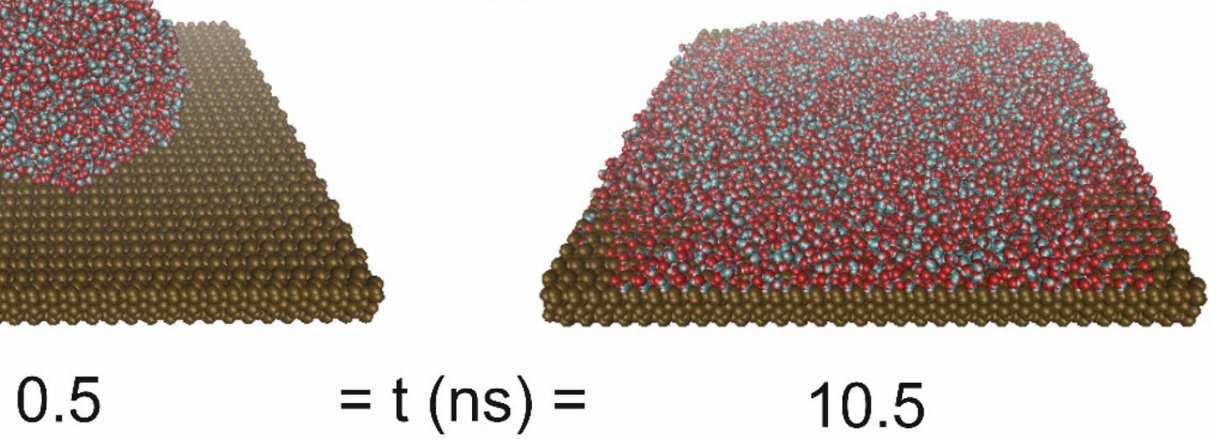

Fig. 4 Snapshots showing the results of MD simulation for water nanodroplet sitting on $\mathrm{Zn}(\mathrm{Cys})_{2}$ surface for two equilibration times at $\mathrm{T}=300 \mathrm{~K}$
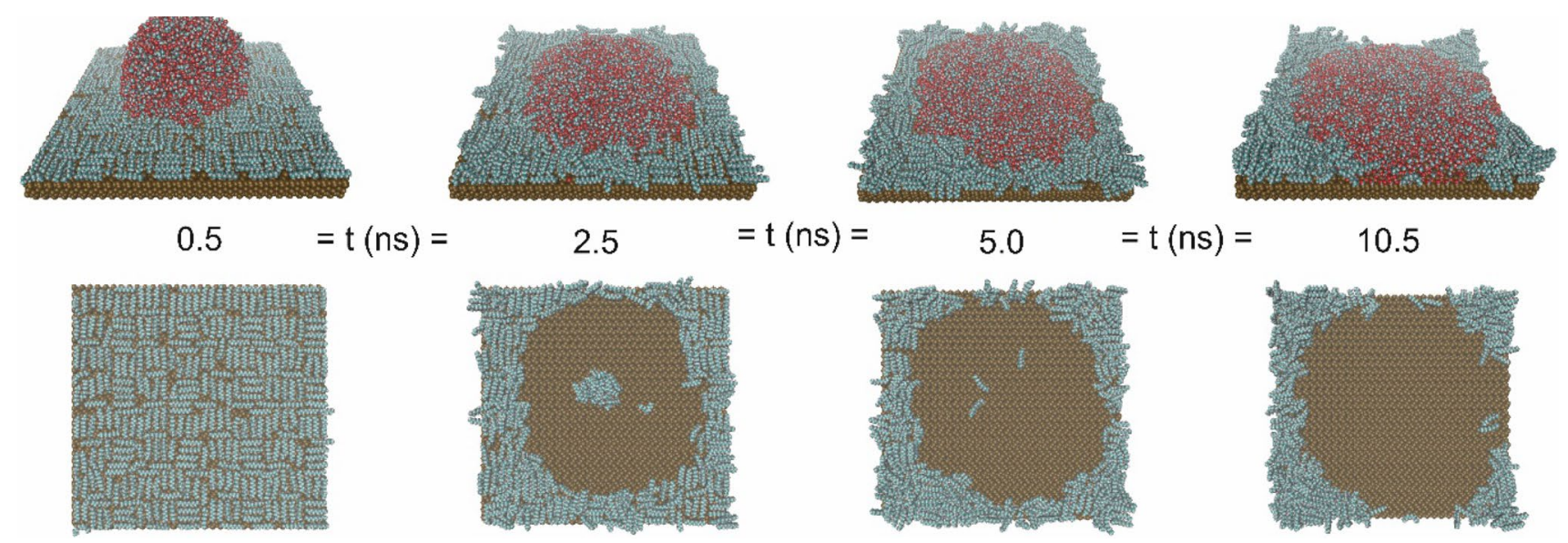

$=t(n s)=$

$5.0=\mathrm{t}(\mathrm{ns})=$

10.5

Fig. 5 Snapshots showing the results of MD simulation for water nanodroplet sitting on $\mathrm{C}_{10} \mathrm{H}_{22}$ - covered (and equilibrated) $\mathrm{Zn}$ (Cys) 2 surface for four equilibration times at $\mathrm{T}=300 \mathrm{~K}$. Bottom panel shows the alkane behaviour under the droplet 

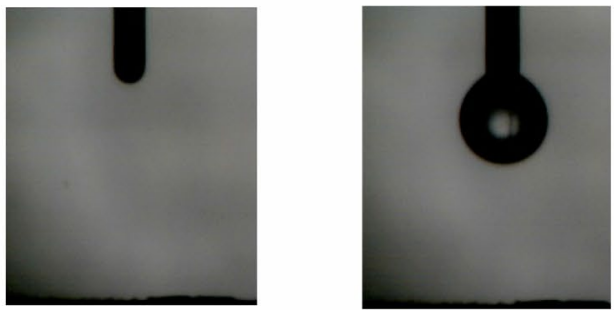

$-1.0=\mathrm{t}(\mathrm{s})=0.0$
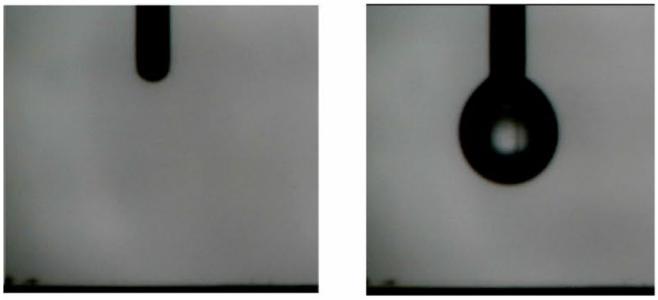

2.0

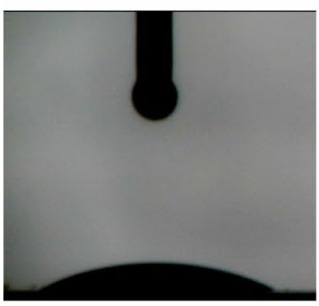

2.5

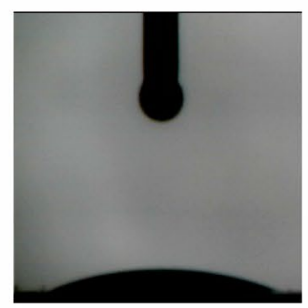

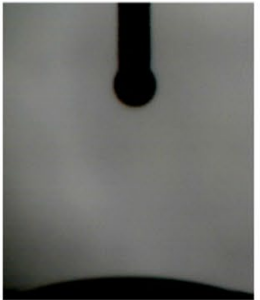

0.5

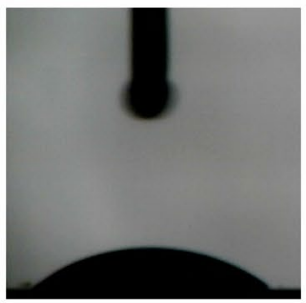

3.5

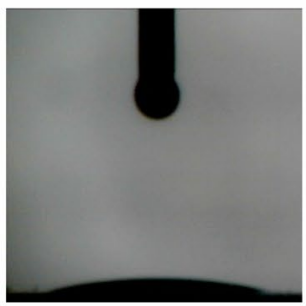

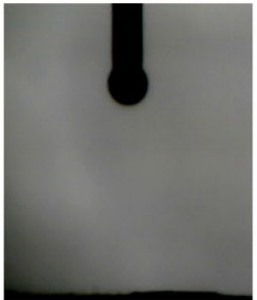

1.0

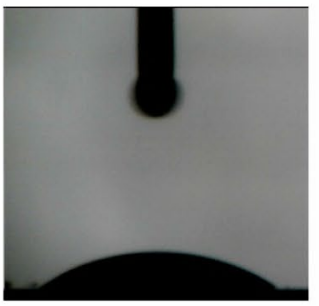

4.5

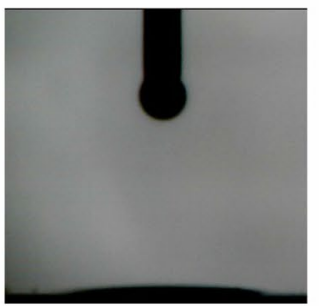

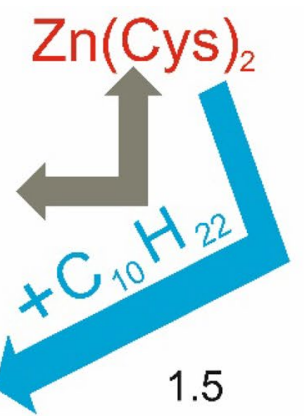

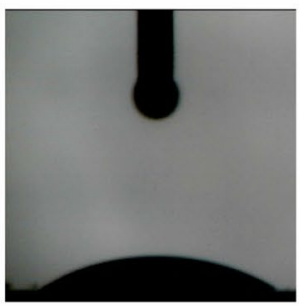

5.5

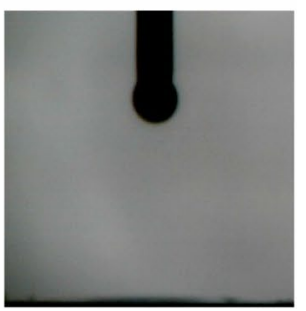

Fig. 6 Snapshots showing the dynamics of wetting by water of the $\mathrm{Zn}(\mathrm{Cys})_{2}$ sample (top panel) and the surface in equilibrium with $\mathrm{C}_{10} \mathrm{H}_{22}$ vapour at the $\mathrm{T}=300 \mathrm{~K}$

of $\mathrm{Zn}(\mathrm{Cys})_{2}$ surface to polar than to nonpolar molecules is confirmed by the MD simulation results showing that even $\mathrm{C}_{55} \mathrm{H}_{112}$ molecules are expelled from the CP surface by water nanodroplet. This finally leads in the macroscale to the faster wetting of a bare $\mathrm{Zn}(\mathrm{Cys})_{2}$ surface than a surface covered by hydrocarbons. Thus studied $\mathrm{CP}$, being strongly water resistant is a promising material for the formation of self-cleaning surfaces and/or coatings. To get a deeper insight into the mechanism of the self-cleaning process further data are necessary and the results will be reported by us in near future.

Acknowledgements This manuscript is dedicated to the memory of our friend and coworker dr hab. Jerzy Włoch who passed away on 12.06.2018. We gratefully acknowledge financial support by the Polish National Science Centre (NCN) Grant OPUS 9 no. 2015/17/B/ ST5/01446, and Grant OPUS 13 UMO-2017/25/B/ST5/00975.

Open Access This article is distributed under the terms of the Creative Commons Attribution 4.0 International License (http://creativeco mmons.org/licenses/by/4.0/), which permits unrestricted use, distribution, and reproduction in any medium, provided you give appropriate credit to the original author(s) and the source, provide a link to the Creative Commons license, and indicate if changes were made.

\section{References}

Abascal, J.L.F., Vega, C.: A general purpose model for the condensed phases of water: TIP4P/2005. J. Chem. Phys. 123, 234505 (2005)

Crick, C.R., Parkin, I.P.: Preparation and characterisation of superhydrophobic surfaces. Chem. Eur. J. 16, 3568-3588 (2010)

Dollimore, D., Heal, G.R., Martin, D.R.: An improvement in the elution technique for measurement of adsorption isotherms by gas chromatography. J. Chromatogr. 50, 209-218 (1970)

Eastman, P., Friedrichs, M.S., Chodera, J.D., Radmer, R.J., Bruns, C.M., Ku, J.P., Beauchamp, K.A., Lane, T.J., Wang, L.-P., Shukla, D., Tye, T., Houston, M., Stich, T., Klein, C., Shirts, M.R., Pande, V.S.: OpenMM 4: a reusable, extensible, hardware independent library for high performance molecular simulation. J. Chem. Theory Comput. 9, 461-469 (2013)

Ferrer, P., da Silva, I., Rubio-Zuazo, J., Castro, G.R.: Synthesis and crystal structure of the novel metal organic framework $\mathrm{Zn}\left(\mathrm{C}_{3} \mathrm{H}_{5} \mathrm{NO}_{2} \mathrm{~S}\right)_{2}$. Powder Diffr. 29, 366-370 (2014)

Furmaniak, S., Gauden, P.A., Terzyk, A.P., Rychlicki, G.: Water adsorption on carbons-critical review of the most popular analytical approaches. Adv. Colloid Interface Sci. 137, 82-143 (2008)

Ganesh, V.A., Raut, H.K., Nair, A.S., Ramakrishna, S.: A review on self-cleaning coatings. J. Mater. Chem. 21, 16304-16322 (2011)

Gilbert, E.P., Reynolds, P.A., White, J.W.: Induced structural changes at aliphatic hydrocarbon-graphite interfaces. Colloids Surf. A 141, 81-100 (1998) 
Grob, R.L.: Physicochemical measurements by gas chromatography. In: Eugene F. Barry, Thomas A. Brettell (eds.) Modern Practice of Gas Chromatography, 3rd edn. Wiley, New York (1995)

He, G., Lu, S., Xu, W., Ye, P., Liu, G., Wang, H., Dai, T.: Stable superhydrophobic $\mathrm{Zn} / \mathrm{ZnO}$ surfaces fabricated via electrodeposition on tin substrate for self-cleaning behavior and switchable wettability. J. Alloys Compd. 747, 772-782 (2018)

Kaner, P., Hu, X., Thomas, S.W., Asatekin, A.: Self-cleaning membranes from comb-shaped copolymers with photoresponsive side groups. ACS Appl. Mater. Interfaces 9, 13619-13631 (2017)

Lagardère, L., Jolly, L.H., Lipparini, F., Aviat, F., Stamm, B., Jing, Z.F., Harger, M., Torabifard, H., Cisneros, G.A., Schnieders, M.J., Gresh, N., Maday, Y., Ren, P.Y., Ponder, J.W., Piquemal, J.P.: Tinker-HP: a massively parallel molecular dynamics package for multiscale simulations of large complex systems with advanced point dipole polarizable force fields. Chem. Sci. 9, 956-972 (2018)

Li, P., Roberts, B.P., Chakravorty, D.K., Merz, K.M. Jr.: Rational design of particle mesh Ewald compatible Lennard-Jones parameters for +2 metal cations in explicit solvent. Chem Theory Comput. 9, 2733-2748 (2013)

Majer, V., Svoboda, V.: Enthalpies of Vaporization of Organic Compounds: A Critical Review and Data Compilation. Blackwell Scientific Publications, Oxford (1985)

Paryjczak, T.: Gas Chromatography in Adsorption and Catalysis. Ellis Horwood, Chichester (1987)

Pifferi, V., Soliveri, G., Panzarasa, G., Ardizzone, S., Cappelletti, G., Meroni, D., Falciola, L.: Electrochemical sensors cleaned by light: a proof of concept for on site applications towards integrated monitoring systems. RSC Adv. 5, 71210-71214 (2015)

Prince, J.A., Bhuvana, S., Anbharasi, V., Ayyanar, N., Boodhoo, K.V.K., Singh, G.: Self-cleaning metal organic framework (MOF) based ultra filtration membranes - a solution to bio-fouling in membrane separation processes. Sci. Rep. 4, 6555 (2014). https ://doi.org/10.1038/srep06555

Robertson, M.J., Tirado-Rives, J., Jorgensen, W.L.: Improved peptide and protein torsional energetics with the OPLSAA force field. J. Chem. Theory Comput. 11, 3499-3509 (2015)

Rosi, N.L., Eckert, J., Eddaoudi, M., Vodak, D.T., Kim, J., O’Keeffe, A., Yaghi, O.M.: Hydrogen storage in microporous metal-organic frameworks. Science 300, 1127-1129 (2003)
Słomkiewicz, P.M.: Determination of the adsorption equilibrium of alcohols and alkenes on a sulphonated styrene-divinylbenzene copolymer. Adsorpt. Sci. Technol. 24, 239-256 (2006)

Varshney, P., Mohapatra, S.S.: Durable and regenerable superhydrophobic coatings for brass surfaces with excellent self-cleaning and anti-fogging properties prepared by immersion technique. Tribol. Int. 123, 17-25 (2018)

Vernov, A., Steele, W.A.: Computer simulations of benzene adsorbed on graphite.2.298 K. Langmuir 7, 2817-2820 (1991)

Włoch, J., Terzyk, A.P., Kowalczyk, P.: New forcefield for water nanodroplet on a graphene surface. Chem. Phys. Lett. 674, 98-102 (2017a)

Włoch, J., Terzyk, A.P., Kowalczyk, P., Korczeniewski, E.D., Kaneko, K.: Switchable hydrophobicity/hydrophilicity of a HOPG surface. Carbon 115, 571-573 (2017b)

Włoch, J., Terzyk, A.P., Wiśniewski, M., Kowalczyk, P.: Nanoscale water contact angle on PTFE surfaces characterized by the MDAFM imaging. Langmuir 34, 4526-4534 (2018)

Yaws, C.L.: Yaws' Handbook of Thermodynamic and Physical Properties of Chemical Compounds: Physical, Thermodynamic and Transport Properties for 5,000 Organic Chemical Compounds. McGraw-Hill, New York (2003)

Yu, M., Chen, S., Zhang, B., Qiu, D., Cui, S.: Why a lotus-like superhydrophobic surface is self-cleaning? An explanation from surface force measurements and analysis. Langmuir 30, 13615-13621 (2014)

Yu, T., Lu, S., Xu, W., He, G.: Fabrication of bismuth superhydrophobic surface on zinc substrate. J. Solid State Chem. 262, 26-37 (2018)

Yusof, N.N., Ghoshal, S.K., Arifin, R., Awang, A., Tewari, H.S., Hamzah, K.: Self-cleaning and spectral attributes of erbium doped sodium-zinc-tellurite glass: role of titania nanoparticles. J. NonCryst. Sol. 481, 225-238 (2018)

Zheng, B., Jiang, G., Wang, W., Mei, X.: Fabrication of superhydrophilic or superhydrophobic self-cleaning metal surfaces using picosecond laser pulses and chemical fluorination. Radiat. Effect Defects Sol. 171, 461-473 (2016) 